heart failure: critical importance of the cardiosplenic axis. Circ Res 2014;114: 266-82.

2. Tarkin JM, Joshi FR, Evans NR, et al. Detection of atherosclerotic inflammation by (68)Ga-DOTATATE PET compared to [(18)F]FDG PET imaging. J Am Coll Cardiol 2017;69:1774-91.

3. Lapa $C$, Reiter $T$, Li X, et al. Imaging of myocardial inflammation with somatostatin receptor based PET/CT-a comparison to cardiac MRI. Int J Cardiol 2015;194:44-9.

4. Thackeray JT, Bankstahl JP, Wang Y, et al. Targeting post-infarct inflammation by PET imaging: comparison of 68Ga-citrate and 68Ga-DOTATATE with 18F-FDG in a mouse model. Eur J Nucl Med Mol Imaging 2014;42:317-27.

5. Quaife-Ryan GA, Sim CB, Ziemann $M$, et al. Multicellular transcriptional analysis of mammalian heart regeneration. Circulation 2017;136:1123-39.

\section{Mini-Sternotomy Versus Conventional Sternotomy for Aortic Valve Replacement}

Outcomes following aortic valve replacement (AVR) surgery are generally excellent, with in-hospital observed mortality in the United Kingdom of $1.5 \%$ for first-time elective procedures (1). These results are not observed in all populations; in high-risk groups, conventional surgery risks perioperative organ injury and prolonged recovery, with death occurring in up to $31 \%$ of patients within 1 year of surgery (2). Minimally invasive surgery combines the durability of surgical repair with reductions in surgical trauma, which together should reduce perioperative morbidity. However, reductions in morbidity and resource use (3) may be confounded by multiple sources of bias and are at odds with the limited evidence from trials that have not shown improved outcomes (4). There is variability in the uptake of minimally invasive surgery internationally, and conventional AVR remains the mainstay for the majority of patients. Minimally invasive surgery requires robust evaluation to better understand its utility.

MAVRIC (Manubrium-limited ministernotomy versus conventional sternotomy for aortic valve replacement) was a single-center, single-blind, randomized superiority trial comparing AVR via manubriumlimited mini-sternotomy using a 5- to $7-\mathrm{cm}$ midline incision (intervention) and conventional median sternotomy using a midline incision from the sternal notch to the xiphisternum (usual care) assessing postoperative red cell transfusion.

The trial was prospectively registered (ISRCTN29567910) and published (5). Patients were stratified by baseline logistic EuroSCORE and hemoglobin and were followed for 12 weeks. The primary outcome was the proportion of patients receiving red cell transfusion within 7 days of surgery.

Using the Fisher exact test with $90 \%$ power, $5 \%$ alpha, we estimated that 260 patients would be required to detect a $17 \%$ reduction in the proportion of patients requiring a red cell transfusion ( $13 \%$ compared with $30 \%$ ), using a 2 -sided test. Allowing for loss to follow-up, the sample size was increased to 270 .

A total of 271 patients were randomized using a computer system with concealed allocation; 270 received surgery and contributed to the intention-totreat analysis. Patients were blinded to the type of sternotomy they received until after they completed their day 2 quality-of-life and pain assessments.

Baseline characteristics were similar between the groups. Mean age $69.3 \pm 9.3$ years (mini-sternotomy group) and $68.7 \pm 8.4$ years (conventional group); range 39 to 88 years. Most were male: $57.8 \%$ (ministernotomy group) versus $64.4 \%$ (conventional group). Mean logistic EuroSCORE was $5.2 \pm 3.5$ (mini-sternotomy group) compared with $5.1 \pm 3.5$ (conventional group), and mean hemoglobin at randomization was $137.9 \pm 14.3 \mathrm{~g} / \mathrm{dl}$ (mini-sternotomy group) and $137.1 \pm 16.1 \mathrm{~g} / \mathrm{dl}$ (conventional group).

No difference between the mini-sternotomy and conventional groups in red cell transfusion within 7 days was found; 23 of 135 patients in each group received a transfusion, odds ratio: 1.0 (95\% confidence interval: 0.5 to 2.0 ), risk difference 0.0 (95\% confidence interval: -0.1 to 0.1 ) (Table 1). Ministernotomy reduced chest drain losses, mean 181.6 $\pm 138.7 \mathrm{ml}$ versus conventional sternotomy, mean $306.9 \pm 348.6 \mathrm{ml}$; this did not reduce red cell transfusions. Mean valve size and post-operative valve function were comparable between mini-sternotomy and conventional groups: $23 \mathrm{~mm}$ versus $24 \mathrm{~mm}$, and 6 of 134 moderate or severe aortic regurgitation versus 3 of 130, respectively. Mini-sternotomy resulted in longer bypass time of $82.7 \pm 23.5 \mathrm{~min}$ versus $59.6 \pm 15.1 \mathrm{~min}$ and cross-clamp time $(64.1 \pm 17.1 \mathrm{~min}$ vs. $46.3 \pm 10.7 \mathrm{~min}$ ). Three experienced consultant cardiac surgeons (E.A., W.A.O., and A.G.), experts at performing both techniques, performed all operations as part of the trial: surgeon A, 58 of each operation; surgeon B, 43 mini-sternotomy and 35 conventional; surgeon C, 34 mini-sternotomy and 42 conventional. A total of 16 patients required conversion from mini to conventional sternotomy; these occurred due to: difficult vascular access $(n=9)$, anesthetic emergency $(n=2)$, and intraoperative complications $(n=5)$. Conventional sternotomy was more costeffective, with a $5.8 \%$ probability of mini-sternotomy being cost-effective at a willingness to pay of $£ 20,000 /$ quality-adjusted life year. 


\begin{tabular}{|c|c|c|c|c|}
\hline & $\begin{array}{c}\text { Mini-Sternotomy } \\
\text { Group }\end{array}$ & $\begin{array}{c}\text { Conventional } \\
\text { Sternotomy Group }\end{array}$ & $\begin{array}{c}\text { Odds Ratio } \\
\text { (95\% Cl; p Value) }\end{array}$ & $\begin{array}{l}\text { Risk Difference } \\
\text { (95\% Cl; p Value) }\end{array}$ \\
\hline \multicolumn{5}{|l|}{ Red cell transfusions } \\
\hline Post-operatively to 7 days & 23/135 (17.0) & 23/135 (17.0) & $1.0(0.5$ to $2.0 ; p=0.9052)$ & 0.0 (-0.1 to $0.1 ; p=0.9999)$ \\
\hline Post-operatively to discharge & $34 / 135(25.2)$ & 29/135 (21.5) & $1.4(0.7-2.7)$ & \\
\hline \multicolumn{5}{|c|}{ Red cell units-post-operatively to 7 days } \\
\hline Number of patients & $23 / 135$ & 23/135 & & \\
\hline Mean \pm SD & $1.6 \pm 0.7$ & $2.3 \pm 1.7$ & & \\
\hline Range (min-max) & $1-3$ & $1-9$ & & \\
\hline \multicolumn{5}{|c|}{ Red cell units-post-operatively to discharge } \\
\hline Number of patients & $34 / 135$ & 29/135 & & \\
\hline Mean \pm SD & $2.5 \pm 2.5$ & $2.6 \pm 2.0$ & & \\
\hline Range (min-max) & $1-13$ & 1-11 & & \\
\hline
\end{tabular}

The primary analysis was conducted under intention-to-treat principles, with all patients analyzed according to their allocated surgery. Results from additional "per-protocol" and "as treated" analyses were consistent with the intention-to-treat results.

MAVRIC differs from previous trials in size and by including a robust expertise-based trial design (adequately powered, randomization with allocation concealment, clarity in outcome measures and assessment, patients blinded to surgical allocation, and a health economic evaluation). The trial had some important limitations, including the singlecenter design; however, this will have biased treatment effect estimates away from the null, at odds with our observed effect.

MAVRIC found no additional clinical benefit of minimally invasive AVR, while increased times on cardiopulmonary bypass were observed. Our results are in agreement with the findings of a recent systematic review (4). These results further indicate that patients should be referred by cardiologists on the basis of a surgeon's experience in performing AVR, not necessarily on the basis of access approach.

\footnotetext{
*Helen C. Hancock, PhD

Rebecca H. Maier, MSc

Adetayo S. Kasim, PhD

James M. Mason, DPhil

Gavin J. Murphy, MD

Andrew T. Goodwin, PhD

W. Andrew Owens, MD

Bilal H. Kirmani, MBChB

Enoch F. Akowuah, MD

*Newcastle University

Faculty of Medical Sciences
}

Newcastle Clinical Trials Unit

Framlington Place

Newcastle upon Tyne, Northumberland NE24HH

United Kingdom

E-mail: helen.hancock@newcastle.ac.uk

Twitter: @UniofNewcastle

https://doi.org/10.1016/j.jacc.2019.03.462

Crown Copyright (c) 2019 Published by Elsevier on behalf of the American College of Cardiology Foundation. All rights reserved

Please note: This trial was supported by the NIHR Research for Patient Benefit Programme (grant number PB-PG-1112-29035). Dr. Murphy is supported by the British Heart Foundation (CH/12/1/29419) and the NIHR Leicester Biomedical Research Centre; and has received research grant funding from Zimmer Biomet for a trial of blood transfusion for a separate trial. Dr. Goodwin has received lecture fees from Medtronic. Dr. Kirmani has been sponsored by Edwards Lifesciences for a minimally invasive fellowship. All other authors have reported that they have no relationships relevant to the contents of this paper to disclose. The views and opinions expressed are those of the authors and do not necessarily reflect those of the National Institute for Health Research (NIHR) Research for Patient Benefit Programme, the National Health Service or the Department of Health and Social Care. The authors are grateful to the patients who agreed to take part in the MAVRIC trial. This trial would not have been possible without the support of all staff in the Cardiothoracic Services in The James Cook University Hospital. The authors would also like to thank Heather Robinson and Jonathan Broughton for their assistance with recruitment, data collection, and data entry; and the team at Durham Clinical Trials Unit, including Jennifer Wilkinson, Andrew Thorpe, Leanne Marsay, and Catherine Frost, for their work in managing the trial and its data. (Manubrium-Limited Ministernotomy Versus Conventional Sternotomy for Aortic Valve Replacement; ISRCTN29567910)

\section{REFERENCES}

1. The Society for Cardiothoracic Surgery in Great Britain \& Ireland. Blue Book Online. Available at: http://bluebook.scts.org/\#. Accessed July 23, 2018.

2. Leontyev $S$, Walther $T$, Borger $M A$, et al. Aortic valve replacement in octogenarians: utility of risk stratification with EuroSCORE. Ann Thorac Surg 2009;87:1440-5.

3. Ghanta RK, Lapar DJ, Kern JA, et al. Minimally invasive aortic valve replacement provides equivalent outcomes at reduced cost compared with conventional aortic valve replacement: A real-world multi-institutional analysis. J Thorac Cardiovasc Surg 2015;149:1060-5.

4. Kirmani BH, Jones SG, Malaisrie SC, Chung DA, Williams RJ. Limited versus full sternotomy for aortic valve replacement. Cochrane Database Syst Rev 2017;4:CD011793

5. Akowuah E, Goodwin AT, Owens WA, et al. Manubrium-limited ministernotomy versus conventional sternotomy for aortic valve replacement (MAV RIC): study protocol for a randomised controlled trial. Trials 2017:18:46. 